\title{
Evaluation of larvicidal activity of the essential oil of Allium macrostemon Bunge and its selected major constituent compounds against Aedes albopictus (Diptera: Culicidae)
}

\author{
Xin Chao Liu', Qiyong Liu², Ligang Zhou ${ }^{3}$ and Zhi Long Liu ${ }^{1 *}$
}

\begin{abstract}
Background: During the screening programme for new agrochemicals from Chinese medicinal herbs and local wild plants, the essential oil of dried bulbs of Allium macrostemon Bunge (Liliaceae) was found to possess larvicidal activity against mosquitoes. The aim of this research was to determine the larvicidal activity of the essential oil and its major constituent compounds against the larvae of the Culicidae mosquito, Aedes albopictus.

Methods: Essential oil of A. macrostemon was obtained by hydrodistillation and analyzed by gas chromatography (GC) and gas chromaotography-mass spectrometry (GC-MS). The activity of the essential oil and its two major constituents were evaluated, using World Health Organization (WHO) procedures, against the fourth instar larvae of Ae. albopictus for $24 \mathrm{~h}$ and larval mortalities were recorded at various essential oil/compound concentrations ranging from $9.0-150 \mu \mathrm{g} / \mathrm{ml}$.

Results: The essential oil of A. macrostemon exhibited larvicidal activity against the early fourth instar larvae of Ae. albopictus with an $\mathrm{LC}_{50}$ value of $72.86 \mu \mathrm{g} / \mathrm{ml}$. The two constituent compounds, dimethyl trisulfide and methyl propyl disulfide possessed strong larvicidal activity against the early fourth instar larvae of Ae. albopictus with $\mathrm{LC}_{50}$ values of $36.36 \mu \mathrm{g} / \mathrm{ml}$ and $86.16 \mu \mathrm{g} / \mathrm{ml}$, respectively.

Conclusion: The results indicated that the essential oil of $A$. macrostemon and its major constituents have good potential as a source for natural larvicides.
\end{abstract}

Keywords: Allium macrostemon, Aedes albopictus, Larvicidal activity, Methyl propyl disulfide, Dimethyl trisulfide

\section{Background}

Females of many species of mosquitoes consume blood from living vertebrates, including humans. They are an important public health concern around the world. In the process of feeding on blood, some of them transmit extremely harmful human diseases, such as yellow fever, dengue fever, malaria, several forms of encephalitis, filariasis and chikungunya [1]. Millions of deaths occur globally each year due to mosquito-borne diseases with a disproportionate effect on children and elders in developing countries [2]. Mosquitoes also cause allergic responses on

\footnotetext{
* Correspondence: zhilongliu@cau.edu.cn

'Department of Entomology, China Agricultural University, Haidian District, Beijing 100193, China

Full list of author information is available at the end of the article
}

humans that include local skin and systemic reactions such as angioedema [3]. The yellow fever mosquito (Aedes aegypti L.) and the Asian tiger mosquito (Ae. albopictus Skuse) are the two main species of mosquito responsible for dengue fever and malaria in China [4]. Mosquito larvae and pupae are currently controlled by the usage of synthetic chemical insecticides organophosphates (e.g. temephos, fenthion, malathion), and insect growth regulators (e.g. diflubenzuron, methoprene). Their repeated use has disrupted the natural biological control systems, sometimes resulting in the widespread development of resistance as well as undesirable effects on nontarget organisms, toxic residues in food, workers' safety, 
and high cost of procurement [5]. These problems have warranted the need for developing alternative strategies using ecofriendly products. From this point of view, botanical pesticides, including essential oils, are promising since they are effective, environmentally friendly, easily biodegradable and often inexpensive. Moreover, herbal sources provide a lead for discovering new insecticides [5]. It is suggested that many essential oils and constituent compounds derived from various essential oils can exert toxic activity against mosquito species [6-11]. During our mass screening program for new agrochemicals from wild plants and Chinese medicinal herbs, essential oil of dried bulbs of Allium macrostemon Bunge (Family: Liliaceae) was found to possess larvicidal activity against the Asian tiger mosquito, Ae. albopictus.

The dried bulbs of $A$. macrostemon are well known as the traditional Chinese medicine "Xie Bai", which is used for the treatment of thoracic pain, stenocardia, heart asthma and diarrhea [12]. The bulbs and leaves, eaten as part of the diet, are emmenagogue, nervine and tonic. When added to the diet on a regular basis, they help to reduce blood cholesterol levels, act as a tonic to the digestive system and also tonify the circulatory system [12]. In the previous reports, various furostanol saponins, steroidal saponins and spirostane saponins have been isolated and identified from the plant [13-26]. Chemical composition of essential oil of A. macrostemon has been analyzed previously [27-29]. Juice of this plant is used as a moth repellent [13]. However, a literature survey has shown that there is no report on insecticidal activity of the essential oil of $A$. macrostemon and its constituent compounds against mosquitoes, thus we decided to investigate the larvicidal activity of the essential oil of A. macrostemon and its major constituents against the Asian tiger mosquito.

\section{Methods}

Plant material

Air-dried bulbs of wild A. macrostemon ( $5 \mathrm{Kg}$, collected during August, 2012, from Baicheng city, Jilin Province, $44.57^{\circ} \mathrm{N}$ latitude and $121.50^{\circ} \mathrm{E}$ longitude) were purchased from the Anguo Medicinal Herb Market, Hebei 071200, China. The plant sample was identified by Dr Liu QR (College of Life Sciences, Beijing Normal University, Beijing 100875, China) and a voucher specimen (CMHXieBai-Liaoning-2012-06) was deposited at the Department of Entomology, China Agricultural University, Beijing, China. The sample was ground to powder using a grinding mill (Retsch Muhle, Haan, Germany) and was subjected to hydrodistillation using a modified Clevenger-type apparatus for $6 \mathrm{~h}$ and extracted with $n$-hexane. Anhydrous sodium sulphate was used to remove water after extraction. Essential oils were stored in airtight containers in a refrigerator at $4^{\circ} \mathrm{C}$ for subsequent experiments.

\section{Gas chromatography-mass spectrometry (GC-MS)}

Profiles of volatile constituents were determined using an Agilent 5973 GC-MS system operating in the EI mode at $70 \mathrm{eV}$ [equipped with a $30 \mathrm{~m}$ HP-5MS column $(0.25 \mathrm{~mm} \times 30 \mathrm{~m} \times 0.25 \mu \mathrm{m})$ and coated with $5 \%$ phenylmethylpolysiloxane using a HP-5MS $(\mathrm{df}=0.25 \mu \mathrm{m})$ (Agilent J\&W Scientific, USA)]. The temperature program used for the analysis was as follows: initial temperature at $60^{\circ} \mathrm{C}$, held for $1 \mathrm{~min}$, ramped at $4^{\circ} \mathrm{C} / \mathrm{min}$ to $290^{\circ} \mathrm{C}$ and held for $0.5 \mathrm{~min}$. Helium was the carrier gas at $1.0 \mathrm{ml} / \mathrm{min}$; the sample $(1 \mu \mathrm{l} 1 / 100, \mathrm{v} / \mathrm{v}$, in acetone $)$ was injected in the split mode (1:10). The injector and detector temperatures were preformed at $230^{\circ} \mathrm{C}$ and $300^{\circ} \mathrm{C}$, respectively. Most constituents were identified by gas chromatography by comparison of their retention indices with those of the literature or with those of authentic compounds available in our laboratories. The retention indices were determined in relation to a homologous series of $n$-alkanes $\left(\mathrm{C}_{8}-\mathrm{C}_{24}\right)$ under the same operating conditions. Further identification was made by comparison of their mass spectra with those stored in NIST 05 and Wiley 275 libraries or with mass spectra from literature [30]. Component relative percentages were calculated based on normalization method without using correction factors.

\section{Insect cultures and rearing conditions}

Mosquito eggs of Ae. albopictus utilized in bioassays were obtained from a laboratory colony maintained in the Department of Vector Biology and Control, Institute for Infectious Disease Control and Prevention, Chinese Center for Disease Control and Prevention. The dehydrated eggs were put into plastic trays containing tap water to hatch and yeast pellets served as food for the emerging larvae. The egg batches, collected daily, were kept wet for $24 \mathrm{~h}$ and then placed in mineral water in the laboratory at $26-28^{\circ} \mathrm{C}$ under natural summer photoperiod for hatching. The newly emerged larvae were then isolated in groups of ten specimens in $100 \mathrm{ml}$ tubes with mineral water and a small amount of dog food. Larvae were controlled daily until they reached the fourth instar, when they were utilized for bioassays (within $12 \mathrm{~h}$ ).

\section{Bioassays}

Range-finding studies were run to determine the appropriate testing concentrations. Concentrations of 150.0, 75.0, $37.5,18.5$, and $9.0 \mu \mathrm{g} / \mathrm{ml}$ of the crude extract/compound were tested. The larval mortality bioassays were carried out according to the test method of larval susceptibility as suggested by the World Health Organization [31]. Twenty larvae were placed in glass beaker with $250 \mathrm{ml}$ of aqueous suspension of test material at various concentrations and an emulsifier (DMSO) was added in the final test solution (less than $0.05 \%$ ). Five replicates were run simultaneously per concentration and with each experiment, a set of 
controls using $0.05 \%$ DMSO and untreated sets of larvae in tap water, were also run for comparison. The two constituents, dimethyl trisulfide (98\%) and methyl propyl disulfide (97\%) were purchased from Aladdin Industrial Inc. (Shanghai, China). For comparison, commercial chlorpyrifos [purchased from National Center of Pesticide Standards (8 Shenliao West Road, Tiexi District, Shenyang 110021, China)] was used as a positive control. The toxicity of chlorpyrifos was determined at $5,2.5,1.25,0.6$, and $0.3 \mu \mathrm{g} / \mathrm{ml}$. The assays were placed in a growth chamber (L16:D9, $26-27^{\circ} \mathrm{C}, 78-80 \%$ relative humidity). Mortality was recorded after $24 \mathrm{~h}$ of exposure and the larvae were starved within this period. The percentage of mortality was corrected for control mortality using Abbott's formula. Results from all replicates for the pure compounds/ oil were subjected to probit analysis using the PriProbit Program V1.6.3 to determine $\mathrm{LC}_{50}$ values and their $95 \%$ confidence intervals [32].

\section{Results and discussion}

\section{Essential oil chemical composition}

The yield of yellow essential oil of A. macrostemon was $0.56 \%(\mathrm{v} / \mathrm{w}$ based on dry weight) while its density was $0.92 \mathrm{~g} / \mathrm{ml}$. A total of 16 components from the essential oil of A. macrostemon were identified, accounting for $98.27 \%$ of the total oil. The principal constituents of A. macrostemon essential oil were methyl propyl disulfide (47.2\%) and dimethyl trisulfide (37.2\%) followed by diallyl thiosulfinate (3.3\%) and 1,3-dithiane (2.6\%) (Table 1). Monoterpenoids only represented 3 of the 16 compounds, corresponding to only $0.29 \%$ of the whole oil, while 13 of the 16 constituents were S-containing compounds $(97.98 \%$ of the crude essential oil). A large variation in the chemical profiles of the A. macrostemon essential oil in this study was observed from those of previous reports [27-29]. For example, dimethyl trisulfide (21.0\%), methyl propyl trisulfide (18.6\%), methyl propyl disulfide (17.0\%) and isopropyl propyl disulfide (10.6\%) were the major compounds in the essential oil of A. macrostemon harvested from Shenyang, Liaoning province, China [27]. However, the essential oil of A. macrostemon collected from Jilin province, China mainly contained dimethyl trisulfide (29.98\%), methyl allyl trisulfide (29.01\%), methyl allyl disulfide (6.87\%), and methyl propyl trisulfide (5.74\%) [28], while the essential oil of A. macrostemon obtained from Sichuan province, China contained methyl allyl trisulfide (20.73\%), dimethyl trisulfide $(16.01 \%)$, dimethyl tetrasulfide $(9.25 \%)$, and dimethyl disulfide (5.62\%) [29]. The results above suggest that there are great variations in chemical composition of essential oil of $A$. macrostemon. This variation could be due to analytic methods, population, different parts used, harvest time and local, climatic and seasonal factors as well as storage duration of medicinal herb. Thus, further studies on plant cultivation and essential oil standardization are needed.
Table 1 Chemical constituents of the essential oil of Allium macrostemon

\begin{tabular}{|c|c|c|c|c|}
\hline Peak no. & Compound & $\mathrm{RI}^{\mathrm{a}}$ & $\mathbf{R I}^{\mathbf{b}}$ & Content (\%) \\
\hline 1 & Diallyl sulfide* & 848 & 848 & 0.34 \\
\hline 2 & Allyl isothiocyanate & 890 & 890 & 0.51 \\
\hline 3 & Methyl allyl disulfide ${ }^{*}$ & 915 & 912 & 1.58 \\
\hline 4 & a-Pinene ${ }^{*}$ & 937 & 939 & 0.14 \\
\hline 5 & Methyl propyl disulfide ${ }^{*}$ & 950 & 946 & 47.23 \\
\hline 6 & Dimethyl trisulfide & 975 & 972 & 37.18 \\
\hline 7 & $\beta$-Pinene ${ }^{*}$ & 980 & 979 & 0.08 \\
\hline 8 & 1,3-Dithiane & 1027 & 1027 & 2.57 \\
\hline 9 & Limonene $^{*}$ & 1029 & 1024 & 0.07 \\
\hline 10 & Diallyl disulfide ${ }^{*}$ & 1077 & 1076 & 1.52 \\
\hline 11 & Methyl allyl trisulfide ${ }^{*}$ & 1134 & 1133 & 0.68 \\
\hline 12 & Methyl propyl trisulfide* & 1168 & 1168 & 1.27 \\
\hline 13 & Dimethyl tetrasulfide & 1214 & 1212 & 0.59 \\
\hline 14 & Diallyl trisulfide ${ }^{*}$ & 1296 & 1289 & 0.52 \\
\hline 15 & Diallyl thiosulfinate & 1325 & 1324 & 3.29 \\
\hline \multirow[t]{4}{*}{16} & Allyl methyl tetrasulfide & 1386 & 1384 & 0.82 \\
\hline & Total identified & & & 98.39 \\
\hline & Monoterpenoids & & & 0.29 \\
\hline & S-Containing compounds & & & 98.10 \\
\hline
\end{tabular}

"Identification by co-injection of authentic compounds; ${ }^{\text {aRl, retention index as }}$ determined on a HP-5MS column using a homologous series of $n$-hydrocarbons;

${ }^{\mathrm{b}} \mathrm{RI}$, retention index reported in the literature [30,33].

\section{Larvicidal activity}

The essential oil of A. macrostemon exhibited larvicidal activity against the early fourth instar larvae of Ae. albopictus with an $\mathrm{LC}_{50}$ value of $72.86 \mu \mathrm{g} / \mathrm{ml}$ (Table 2). The two constituent compounds, dimethyl trisulfide and methyl propyl disulfide possessed strong larvicidal activity against the early fourth instar larvae of Ae. albopictus with $\mathrm{LC}_{50}$ values of $36.36 \mu \mathrm{g} / \mathrm{ml}$ and $86.16 \mu \mathrm{g} / \mathrm{ml}$, respectively

Table 2 Larvicidal activity of the essential oil of Allium macrostemon and its major constituents against fourth-instar larvae of Aedes albopictus

\begin{tabular}{|c|c|c|c|c|}
\hline Treatment & $\begin{array}{c}\mathrm{LC}_{50} \\
(\mu \mathrm{g} / \mathrm{ml}) \\
(95 \% \mathrm{CL})\end{array}$ & $\begin{array}{c}\mathrm{LC}_{95} \\
(\mu \mathrm{g} / \mathrm{ml}) \\
(95 \% \mathrm{CL})\end{array}$ & Slope \pm SD & $\begin{array}{c}\text { Chi-square } \\
\text { value }\end{array}$ \\
\hline Essential oil & $\begin{array}{c}72.86 \\
(66.02-78.67)\end{array}$ & $\begin{array}{c}132.84 \\
(126.76-145.17)\end{array}$ & $2.72 \pm 0.27$ & $7.73^{*}$ \\
\hline $\begin{array}{l}\text { Dimethyl } \\
\text { trisulfide }\end{array}$ & $\begin{array}{c}36.36 \\
(33.23-39.64)\end{array}$ & $\begin{array}{c}55.65 \\
(49.43-61.27)\end{array}$ & $2.61 \pm 0.26$ & $10.60^{*}$ \\
\hline $\begin{array}{l}\text { Methyl propyl } \\
\text { disulfide }\end{array}$ & $\begin{array}{c}86.16 \\
(79.53-91.43)\end{array}$ & $\begin{array}{c}144.16 \\
(130.22-155.82)\end{array}$ & $2.59 \pm 0.25$ & $8.94^{*}$ \\
\hline Chlorpyrifos & $\begin{array}{c}1.86 \\
(1.71-2.05)\end{array}$ & $\begin{array}{c}6.65 \\
(6.21-7.48)\end{array}$ & $0.87 \pm 0.01$ & $3.13^{*}$ \\
\hline
\end{tabular}

*Significant at $P<0.05$ level. 
(Table 2). The commercial insecticide, chlorpyrifos showed larvicidal activity against the mosquitoes with a $\mathrm{LC}_{50}$ value of $1.86 \mu \mathrm{g} / \mathrm{ml}$, thus the essential oil of $A$. macrostemon was 39 times less toxic to Ae. albopictus larvae compared with chlorpyrifos. However, compared with the other essential oils/extracts in the literature, essential oil of $A$. macrostemon exhibited stronger or the same level of larvicidal activity against Ae. albopictus larvae, e.g. essential oils of Eucalyptus urophylla $\left(\mathrm{LC}_{50}=95.5 \mu \mathrm{g} / \mathrm{ml}\right)$ [34]; essential oils of Achillea millefolium $\left(\mathrm{LC}_{50}=211.3 \mu \mathrm{g} / \mathrm{ml}\right)$, Helichrysum italicum $\left(\mathrm{LC}_{50}=178.1 \mu \mathrm{g} / \mathrm{ml}\right)$, Foeniculum vulgare $\left(\mathrm{LC}_{50}=142.9 \mu \mathrm{g} / \mathrm{ml}\right)$ [35]; ethanol extract from Cryptomeria japonica $\left(\mathrm{LC}_{50}=93.8 \mu \mathrm{g} / \mathrm{ml}\right)$ [36], and ethanol extract of Knema attenuata $\left(\mathrm{LC}_{50}=141 \mathrm{ppm}\right)$ [37] as well as a solution of $80 \%$ ethanol extract of fresh garlic (Allium sativum) [38]. Among the two constituent compounds, methyl propyl disulfide exhibited almost the same level of larvicidal activity as the essential oil and dimethyl trisulfide possessed stronger larvicidal activity than the crude oil against Ae. albopictus larvae. Moreover, compared with chlorpyrifos, dimethyl trisulfide exhibited 19 times less toxicity against Ae. albopictus larvae (Table 2).

In the previous reports, the two constituents exhibited antimicrobial activities against several bacteria and fungi as well as nematodes [39-42]. There are numerous reports on insecticidal activity of sulfide-containing compounds against pests including the two constituent compounds. For example, dimethyl trisulfide was demonstrated to exhibit toxicity to African cowpea bruchid (Bruchidius atrolineatus) [43]. Dimethyl trisulfide and methyl propyl disulfide also exhibited larvicidal activity against the yellow fever mosquito (Ae. aegypti) [44,45]. The above findings suggest that the essential oil and the two major constituent compounds show the potential to be developed as possible natural larvicides for the control of mosquitoes.

It seems that this plant is quite safe for human consumption because it has been used as a common vegetable or spice in Chinese food [46] and also as a medicinal herb for the treatment of thoracic pain, stenocardia, heart asthma and diarrhea [12]. Dimethyl trisulfide and methyl propyl disulfide can be used as food additives and flavours in China. However, no information on toxicity of the essential oil and the isolated constituents to humans are available. Thus, to develop a practical application for the essential oil and its constituents as novel insecticides, further research into the safety of the essential oil/compounds to humans is needed. Additional studies on the development of formulations are also necessary to improve the efficacy and stability and to reduce costs. Moreover, field evaluation and further investigations on the effects of the essential oil and its constituent compounds on non-target organisms are necessary.

\section{Conclusions}

The essential oil of Allium macrostemon bulbs and its two major constituents demonstrate strong larvicidal activity against Aedes albopictus mosquito larva. Our results suggested that the essential oil of $A$. macrostemon and the two major constituents may be recommended effectively in mosquito control program but needs to be further evaluated for safety in humans and to enhance their activity.

\section{Competing interests}

The authors declare that they have no competing interests.

\section{Authors' contributions}

ZLL designed the work and supervised the manuscript. XCL, QL and $\mathrm{LZ}$ performed experiments, interpretation of data and drafted the manuscript. All authors read and approved the final version of the manuscript.

\section{Acknowledgements}

This work was funded by the Hi-Tech Research and Development of China 2011AA10A202. We thank Dr. QR Liu from College of Life Sciences, Beijing Normal University, Beijing 100875, for the identification of the investigated medicinal herb.

\section{Author details}

'Department of Entomology, China Agricultural University, Haidian District, Beijing 100193, China. ${ }^{2}$ State Key Laboratory for Infectious Disease Prevention and Control, National Institute for Communicable Disease Control and Prevention, Chinese Center for Disease Control and Prevention, Beijing 102206, China. ${ }^{3}$ Department of Plant Pathology, China Agricultural University, Haidian District, Beijing 100193, China.

Received: 28 February 2014 Accepted: 9 April 2014

Published: 15 April 2014

References

1. Cheng SS, Huang CG, Chen WJ, Kuo YH, Chang ST: Larvicidal activity of tectoquinone isolated from red heartwood-type Cryptomeria japonica against two mosquito species. Bioresour Technol 2008, 99:3617-3622.

2. Githeko AK, Lindsay SW, Confalonieri UE, Patz JA: Climate change and vector-borne diseases: a regional analysis. Bull World Health Organ 2000, 78:1136-1147.

3. Peng $Z$, Yang J, Wang $H$, Simons FER: Production and characterization of monoclonal antibodies to two new mosquito Aedes aegypti salivary proteins. Insect Biochem Mol Biol 1999, 29:909-914.

4. Liu ZL, Liu QZ, Du SS, Deng ZW: Mosquito larvicidal activity of alkaloids and limonoids derived from Evodia rutaecarpa unripe fruits against Aedes albopictus (Diptera: Culicidae). Parasitol Res 2012, 111:991-996.

5. Isman MB: Botanical insecticides, deterrents, and repellents in modern agriculture and an increasingly regulated world. Ann Rev Entomol 2006, 51:45-66.

6. Silva AJ, Almeida DL, Ronchi SN, Bento AC, Scherer R, Ramos AC, Cruz ZMA: The essential oil of Brazilian pepper, Schinus terebinthifolia Raddi in larval control of Stegomyia aegypti (Linnaeus, 1762). Parasit Vectors 2010, 3:79.

7. Kweka EJ, Nyindo M, Mosha F, Silva AJ: Insecticidal activity of the essential oil from fruits and seeds of Schinus terebinthifolia Raddi against African malaria vectors. Parasit Vectors 2011, 4:129.

8. Kweka EJ, Senthilkumar A, Venkatesalu V: Toxicity of essential oil from Indian borage on the larvae of the African malaria vector mosquito, Anopheles gambiae. Parasit Vectors 2012, 5:277.

9. Liu ZL, He Q, Chu SS, Wang CF, Du SS, Deng ZW: Essential oil composition and larvicidal activity of Saussurea lappa roots against the mosquito Aedes albopictus (Diptera: Culicidae). Parasitol Res 2012, 110:2125-2130.

10. Liu XC, Dong HW, Zhou L, Du SS, Liu ZL: Essential oil composition and larvicidal activity of Toddalia asiatica roots against the mosquito Aedes albopictus (Diptera: Culicidae). Parasitol Res 2013, 112:1197-1203.

11. Dua VK, Kumar A, Pandey AC, Kumar S: Insecticidal and genotoxic activity of Psoralea corylifolia Linn. (Fabaceae) against Culex quinquefasciatus Say, 1823. Parasit Vectors 2013, 6:30. 
12. Jiangsu New Medical College: Dictionary of Chinese Herbal Medicine. Shanghai, China: Shanghai Science \& Technology Press; 2001:2642-2643.

13. Cheng SB, Wang Y, Zhang YF, Wang Y: Steroidal saponins from Bulbus Allii Macrostemonis. Chin Tradit Herb Drugs 2013, 44:1078-1081.

14. Chen HF, Ou WC, Wang GH, Wang NL, Zhang LN, Yao XS: New steroidal glycosides isolated as CD40L inhibitors of activated platelets. Molecules 2010, 15:4589-4598

15. Chen HF, Wang GH, Luo Q, Wang NL, Yao XS: Two new steroidal saponins from Allium macrostemon Bunge and their cytotoxity on different cancer cell lines. Molecules 2009, 14:2246-2253.

16. Chen HF, Wang GH, Wang NL, Yang MS, Wang Z, Wang XW, Yao XS: New furostanol saponins from the bulbs of Allium macrostemon Bunge and their cytotoxic activity. Pharmazie 2007, 62:544-548.

17. Chen HF, Wang NL, Sun HL, Yang BF, Yao XS: Novel furostanol saponins from the bulbs of Allium macrostemon B. and their bioactivity on $\left[\mathrm{Ca}^{2+}\right]$ increase induced by $\mathrm{KCl}$. J Asian Nat Prod Res 2006, 8:21-28.

18. Peng JP, Yao XS, Okada Y, Okuyama T: Further studies on new furostanol saponins from the bulbs of Allium macrostemon. Chem Pharm Bull 1994, 42:2180-2182

19. Peng JP, Yao XS, Kobayashi $\mathrm{H}, \mathrm{Ma} \mathrm{CY}$ : Novel furostanol glycosides from Allium macrostemon. Planta Med 1995, 61:58-61.

20. Peng JP, Yao XS, Okada Y, Okuyama T: Structures of macrostemonoside J, $\mathrm{K}$ and L from Allium macrostemon Bunge. Acta Pharm Sin 1994, 29:526-531.

21. Peng JP, Wang $X$, Yao XS: Studies of two new furostanol glycosides from Allium macrostemon Bunge. Chin Chem Lett 1993, 4:141-144.

22. Peng JP, Wang $X$, Yao XS: New furostanol glycosides from Allium macrostemon Bunge. Acta Pharm Sin 1993, 28:526-531.

23. Peng JP, Wu Y, Yao XS, Okada Y, Okuyama T: Two new steroidal saponins from Allium macrostemon. Acta Pharm Sin 1992, 12:918-922.

24. Wu Y, Peng JP, Yao XS, Okuyama T, Narui T: Macrostemonoside A: a new spirostane saponin from Allium macrostemon Bge. J Shenyang Pharm Univ 1992, 9:69-70

25. Peng JP, Wu Y, Yao XS, Okuyama T, Narui T: Two new steroidal saponins from the bulbs of Allium macrostemon Bunge. Chin Chem Lett 1992, 3:285-286.

26. Ou WC, Chen HF, Zhong Y, Liu BR, Liu SM, Chen KJ: Inhibition of platelet activation and aggregation by furostanol saponins isolated from the bulbs of Allium macrostemon Bunge. Am J Med Sci 2012, 344:261-267.

27. Wu Y, Peng JP, Yao LQ, Yao XS: Volatile oils of Allium macrostemon Bunge. J Shenyang Pharm Univ 1993, 10:45-46.

28. Gu YQ, Liu YY, Yang XH, Chen D, Fu FH: Effect of the essential oils of Allium cepa L. var. agrgatum Don and Allium macrostemon Bunge on arachidonic acid metabolism. Acta Pharm Sin 1988, 23:8-11.

29. Lin L, Jiang HZ, Luo LQ, Xu HG, Hu K, Geng Y: GC-MS analysis of the volatile oil from Bulbus Allii Macrostemonis extracted by supercritical carbon dioxide. Chin J Anal Lab 2008, 27:115-118.

30. Adams RP: Identification of Essential Oil Components by Gas Chromatography/ Mass Spectroscopy. Carol Stream, IL, USA: Allured; 2007.

31. World Health Organization: Instruction for determining the susceptibility or resistance of mosquito larvae to insecticide. Geneva: World Health Organization; 1981. WHO/NBC/81.80, http://www.who.int/iris/handle/10665/69619

32. Sakuma M: Probit analysis of preference data. Appl Entomol Zool 1998, 33:39-347.

33. Iranshahi M: A review of volatile sulfur-containing compounds from terrestrial plants: biosynthesis, distribution and analytical methods. J Essent Oil Res 2012, 24:393-434.

34. Cheng SS, Huang CG, Chen YJ, Yu JJ, Chen WJ, Chang ST: Chemical compositions and larvicidal activities of leaf essential oils from two eucalyptus species. Bioresour Technol 2009, 100:452-456.

35. Conti B, Canale A, Bertoli A, Gozzini F, Pistelli L: Essential oil composition and larvicidal activity of six Mediterranean aromatic plants against the mosquito Aedes albopictus (Diptera: Culicidae). Parasitol Res 2010, 107:1455-1461.

36. Gu HJ, Cheng SS, Huang CG, Chen WJ, Chang ST: Mosquito larvicidal activities of extractives from black heartwood-type Cryptomeria japonica. Parasitol Res 2009, 105:1455-1458.

37. Vinayachandra, Shwetha R, Chandrashekar KR: Larvicidal activities of Knema attenuata (Hook. f. \& Thomson) Warb. (Myristicaceae) extracts against Aedes albopictus Skuse and Anopheles stephensi Liston. Parasitol Res 2011, 109:1671-1676.
38. Kyung KH, Fleming HP: Antimicrobial activity of sulfur compounds derived from cabbage. J Food Prot 1997, 60:67-71.

39. Tedeschi P, Leis M, Pezzi M, Civolani S, Maietti A, Brandolini V: Insecticidal activity and fungitoxicity of plant extracts and components of horseradish (Armoracia rusticana) and garlic (Allium sativum). J Environ Sci Health 2011, 46B:486-490.

40. Ross ZM, O'Gara EA, Hill DJ, Sleightholme HV, Maslin DJ: Antimicrobial properties of garlic oil against human enteric bacteria: evaluation of methodologies and comparisons with garlic oil sulfides and garlic powder. Appl Environ Microbiol 2001, 67:475-480.

41. Tada M, Hiroe Y, Kiyohara S, Suzuki S: Nematicidal and antimicrobial constituents from Allium grayi Regel and Allium fistulosum L. var. caespitosum. Agric Biol Chem 1988, 52:2383-2385.

42. Zhang $H$, Mallik A, Zeng RS: Control of panama disease of banana by rotating and intercropping with Chinese chive (Allium tuberosum Rottler): role of plant volatiles. J Chem Ecol 2013, 39:243-252.

43. Nammour D, Auger J, Huignard J: Insecticidal effect of sulfur compounds (disulfides and trisulfides) on Bruchidius atrolineatus (Pic) (Coleoptera, Bruchidae). Insect Sci Its Appl 1989, 10:49-53.

44. Chung IM, Song HK, Yeo MA, Moon HI: Composition and immunotoxicity activity of major essential oils from stems of Allium victorialis L. var. platyphyllum Makino against Aedes aegypti L. Immunopharm Immunotoxicol 2011, 33:480-483.

45. Moon HI: Larvicidal activity of major essential oils from stems of Allium monanthum Maxim. against Aedes aegypti L. J Enzyme Inhib Med Chem 2011, 26:827-830

46. Editorial Committee of Flora Reipublicae Popularis Sinicae: Flora Reipublicae Popularis Sinicae Vol. 14. Beijing: Science Press; 1980:265-266.

doi:10.1186/1756-3305-7-184

Cite this article as: Liu et al:: Evaluation of larvicidal activity of the essential oil of Allium macrostemon Bunge and its selected major constituent compounds against Aedes albopictus (Diptera: Culicidae). Parasites \& Vectors 2014 7:184

\section{Submit your next manuscript to BioMed Central and take full advantage of:}

- Convenient online submission

- Thorough peer review

- No space constraints or color figure charges

- Immediate publication on acceptance

- Inclusion in PubMed, CAS, Scopus and Google Scholar

- Research which is freely available for redistribution 